\title{
Overexpression of miR-25 is associated with progression and poor prognosis of cholangiocarcinoma
}

\author{
HAIBO LIU* ${ }^{*}$ LUJUAN MA* and JIAN WANG \\ Department of Laboratory Medicine, Yidu Central Hospital of Weifang, Weifang, Shandong 262500, P.R. China
}

Received November 1, 2018; Accepted June 20, 2019

DOI: $10.3892 /$ etm.2019.7844

\begin{abstract}
Cholangiocarcinoma (CCA) is a rare but highly aggressive type of malignancy. MicroRNA (miR)-25 has been demonstrated to be involved in the genesis of numerous cancer types. The aim of the present study was to investigate the prognostic value and functional role of miR-25 in CCA. The expression of miR-25 was determined by reverse transcription-quantitative (RT-q)PCR. The association between miR-25 expression and clinicopathological features was analyzed using the $\chi^{2}$ test. Kaplan-Meier survival analysis and Cox linear regression were performed to explore the prognostic value of miR-25. The effects of miR-25 on the biological behavior of CCA cells were determined using loss-and gain-of-function experiments in CCA cell lines. Upregulated miR-25 expression was observed in CCA tissues and cell lines compared with that in the respective controls (all $\mathrm{P}<0.05$ ). Patients with high expression of miR-25 in CCA tissues had a comparatively higher tumor-nodes-metastasis stage $(\mathrm{P}=0.026)$, a higher rate of lymph node metastasis $(\mathrm{P}=0.032)$ and a shorter overall survival rate $(\log$-rank $\mathrm{P}=0.022)$. miR-25 was determined to be an independent prognostic factor for CCA patients $(\mathrm{P}=0.036)$. In vitro, transfection with miR-25 inhibitor suppressed cell viability, migration and invasion, while miR-25 mimics had the opposite effect. These results indicated that miR-25 functions as an oncogene and is involved in tumor progression in CCA. miR-25 may serve as a prognostic biomarker and a potential therapeutic target for CCA treatment.
\end{abstract}

\section{Introduction}

Cholangiocarcinoma (CCA), a highly aggressive type of malignancy, is an epithelial cancer of the biliary tree (1). According

Correspondence to: Dr Jian Wang, Department of Laboratory Medicine, Yidu Central Hospital of Weifang, 4,138 South Linglongshan Road, Weifang, Shandong 262500, P.R. China

E-mail: zou8402pidao@163.com

*Contributed equally

Key words: microRNA-25, prognosis, viability, migration, invasion, cholangiocarcinoma to its anatomical location, CCA is classified into two major types, including the extrahepatic type and the intrahepatic type, of which the extrahepatic type is more common. In recent decades, the incidence and mortality of CCA, particularly the intrahepatic type, has significantly increased worldwide (2). As patients in the early stages of CCA are frequently asymptomatic, CCA is usually diagnosed in the late stages, resulting in a dismal survival rate and prognosis $(3,4)$. Furthermore, almost all types of CCA are resistant to chemotherapies and radical surgery may be the only effective treatment for CCA. This provides patients with only a small benefit, given that they are diagnosed at an advanced stage $(5,6)$. Therefore, it is crucial to explore novel cancer-associated genes that may serve as reliable diagnostic or prognostic biomarkers and therapeutic targets for improving the prognosis and therapeutic efficacy.

MicroRNAs (miRNAs/miRs) are a group of small, endogenous non-coding RNA molecules that regulate the expression of target genes at the post-transcriptional level. miRNAs are involved in the regulation of various physiological and pathological functions $(7,8)$. They have crucial roles in various biological processes, including inflammation, cell proliferation, migration, invasion and differentiation (9-12). Previous studies have indicated that miR-25 is overexpressed in a variety of cancer types and is functionally associated with numerous cancer-associated processes, including cancer cell proliferation, migration and metastasis (13-16). However, the current knowledge on the role of miR-25 in CCA is limited.

In the present study, the expression pattern of miR-25 in CCA tissues and cell lines was investigated. The association between miR-25 expression and clinical characteristics was also analyzed. The effects of miR-25 on the biological behavior of cancer cells were investigated through in vitro cell experiments. Furthermore, the clinical significance of miR-25 as a potential prognostic biomarker for CCA patients was evaluated.

\section{Materials and methods}

Patients and tissue samples. The present study included 116 patients diagnosed with CCA treated at Yidu Central Hospital (Weifang, China) between February 2007 and October 2012. The CCA tissues and corresponding adjacent non-tumorous tissues were snap-frozen in liquid nitrogen after collection. None of the patients enrolled received any treatment prior to surgery. The 5-year follow-up information was collected for 
subsequent analysis. The clinicopathological characteristics of the cohort are summarized in Table I.

Cell lines and transfection. The human CCA cell lines CCLP1 and HuCCT1 were purchased from the Japan Health Science Research Resources Bank. A normal human intrahepatic biliary epithelial cell line (HIBEC) (17) was purchased from the American Type Culture Collection. These cell lines were cultured in RPMI-1640 medium (Invitrogen; Thermo Fisher Scientific, Inc.) with $10 \%$ fetal bovine serum (FBS, Invitrogen, Thermo Fisher Scientific, Inc.) and were incubated at $37^{\circ} \mathrm{C}$ in a humidified incubator with $5 \% \mathrm{CO}_{2}$. miR-25 mimics (5'-AGG CGGAGACUUGGGCAAUUG-3'), mimics negative control (mimics NC, 5'-UUCUCCGAACGUGUCACGUTT-3'), miR-25 inhibitor (5'-CAAUUGCCCAAGUCUCCGCCU-3') or inhibitor negative control (inhibitor NC, 5'-CAGUAC UUUUGUGUAGUACAA-3') were obtained from Shanghai GenePharma Co., Ltd. Cell transfection was performed using the Lipofectamine 2000 Reagent (Invitrogen; Thermo Fisher Scientific, Inc.) following the manufacturer's protocols. A total of $5 \times 10^{4}$ cells were seeded into the wells of a 6 -well plate and after $24 \mathrm{~h}$, the cells were transfected with miR-25 mimics or mimics NC, miR-25 inhibitor or inhibitor NC for $48 \mathrm{~h}$. Cells with only transfection reagent were used as a mock group. Reverse transcription-quantitative (RT-q)PCR analysis was used to detect the successful knockdown or upregulation of miR-25 expression.

RNA extraction and RT-qPCR analysis. Total RNA was extracted from the tissues and cells using TRIzol reagent (Invitrogen; Thermo Fisher Scientific, Inc.) according to the manufacturer's protocol. The miRNA of the purified total RNA was then reverse-transcribed to complementary DNA (cDNA) by using the Transcriptor First Strand cDNA Synthesis Kit (Roche). The relative miR-25 expression was analyzed by using the qPCR analysis, which was performed using SYBR Green (Takara Bio, Inc.) on an ABI 7500 system (Applied Biosystems; Thermo Fisher Scientific, Inc.). The thermocycling conditions were as follows: Initial denaturation at $95^{\circ} \mathrm{C}$ for $5 \mathrm{~min} ; 40$ cycles of $95^{\circ} \mathrm{C}$ for $30 \mathrm{sec}, 60^{\circ} \mathrm{C}$ for $30 \mathrm{sec}$, and $72^{\circ} \mathrm{C}$ for $10 \mathrm{sec}$; final extension at $72^{\circ} \mathrm{C}$ for $10 \mathrm{~min}$. The primers were as follows: miR-25, 5'-GTGTTGAGAGGGCGG AGACTT-3' (forward) and 5'-TCAGACCGAGACAAGTGC AA-3' (reverse); U6, 5'-GCTTCGGCAGCACATATACTA AAAT-3' (forward) and 5'-CGCTTCACGAATTTGCGTGTC AT-3' (reverse). Relative expression was calculated using the $2^{-\Delta \Delta \mathrm{Cq}}$ method (18) with normalization to U6. Each experiment was performed as three replicates.

MTT cell viability assay. The colorimetric MTT assay was used to evaluate the effect of miR-25 on the viability of CCA cells. CCLP-1 and HuCCT1 cells were seeded in 96-well plates $\left(5 \times 10^{4}\right.$ per well). After transfection, $10 \mu \mathrm{l} \mathrm{MTT}(5 \mathrm{mg} / \mathrm{ml}$; Sigma-Aldrich; Merck KGaA) was added to each well and the cells were incubated at $37^{\circ} \mathrm{C}$ for $4 \mathrm{~h}$. The medium was then removed and $150 \mu \mathrm{l}$ DMSO (Sigma-Aldrich; Merck KGaA) was added to each well to dissolve the formazan crystals. The absorbance of each well at a wavelength of $490 \mathrm{~nm}$ was measured with a spectrophotometer (Multiskan MK3; Thermo Fisher Scientific, Inc.).
Colony formation assay. After transfection with miR-25 mimics, mimics NC, miR-25 inhibitor or inhibitor NC for 48 h, CCLP-1 and HuCCT1 cells were seeded in 6-well culture plated at a density of 300 cells/well and incubated in complete medium at $37^{\circ} \mathrm{C}$ for $24 \mathrm{~h}$. The medium was removed, and the cells were washed in PBS and incubated in complete medium for 14 days. Subsequently, the cells were washed carefully with PBS, fixed with methanol for 15 min and stained with Giemsa for $10 \mathrm{~min}$ at room temperature. The numbers of colonies (>50 cells) were counted. All experiments were performed in triplicate.

Transwell migration and invasion assay. The migration and invasion of CCA cells were measured using a Transwell assay (Corning, Inc.; $8.0 \mu \mathrm{m}$ pores). CCLP-1 and HuCCT1 cells were transfected for $24 \mathrm{~h}$, harvested and suspended to a final concentration of $2 \times 10^{5}$ cells in $100 \mu 1$ serum-free RPMI-1640 medium, which were added and incubated in the top chamber with the serum-free RPMI-1640 medium at $37^{\circ} \mathrm{C}$ for $24 \mathrm{~h}$. RPMI 1640 with $20 \%$ FBS used as the chemotactic factor was added to the bottom chamber. For the invasion assay, the upper chamber was first coated with Matrigel. For the migration assay, no Matrigel was added to the upper chamber. The cells that had migrated or invaded to the bottom chamber were fixed in $3.7 \%$ formaldehyde for $5 \mathrm{~min}$ at room temperature and stained with $0.1 \%$ crystal violet for $15 \mathrm{~min}$ at room temperature and counted under a microscope (Olympus Corp.) in five random fields of view.

Statistical analysis. Statistical analysis was performed using SPSS 21.0 software (IBM Corp.). Values are expressed as the mean \pm standard deviation. Differences between groups were analyzed by a paired Student's t-test or one-way analysis of variance. The association between miR-25 expression and the clinicopathological parameters of patients was analyzed using the $\chi^{2}$ test. Survival curves were drawn using the Kaplan-Meier method and statistically compared using the log-rank test. Prognostic factors were determined using Cox regression analysis. $\mathrm{P}<0.05$ was considered to indicate statistical significance.

\section{Results}

Expression levels of miR-25 in CCA tissues and cell lines. The miR-25 expression in CCA tissues and cell lines was examined by RT-qPCR. The results suggested that the expression levels of miR-25 in the tissues were significantly higher than those in normal tissues $(\mathrm{P}<0.001$; Fig. 1A). Furthermore, the expression levels of miR-25 in CCLP1 cells and HuCCT1 cells were significantly higher than those in normal HIBECs (all $\mathrm{P}<0.01$; Fig. 1B).

Association between miR-25 expression and clinicopathological features of CCA patients. It was then investigated whether miR-25 expression is associated with the clinicopathological characteristics of the CCA patients. For this, the CCA patients were divided into a low miR-25 expression group $(\mathrm{n}=51)$ and a high expression group $(n=65)$ according to the mean value of relative miR-25 expression in CCA tissues (2.219) as a cutoff. As presented in Table I, high expression of miR-25 was closely associated with tumor-nodes-metastasis (TNM) stage 
Table I. Association between miR-25 expression and clinicopathological parameters of patients with cholangiocarcinoma $(\mathrm{n}=116)$.

miR-25 expression

\begin{tabular}{|c|c|c|c|c|}
\hline & & & & \\
\hline Characteristics & $\mathrm{N}$ & Low $(n=51)$ & $\operatorname{High}(\mathrm{n}=65)$ & P-value \\
\hline Age (years) & & & & 0.887 \\
\hline$<60$ & 56 & 25 & 31 & \\
\hline$\geq 60$ & 60 & 26 & 34 & \\
\hline Sex & & & & 0.733 \\
\hline Male & 68 & 29 & 39 & \\
\hline Female & 48 & 22 & 26 & \\
\hline Differentiation & & & & 0.096 \\
\hline Well & 65 & 33 & 32 & \\
\hline Moderate + poor & 51 & 18 & 33 & \\
\hline TNM stage & & & & 0.026 \\
\hline I-II & 57 & 31 & 26 & \\
\hline III-IV & 59 & 20 & 39 & \\
\hline Lymph node metastasis & & & & 0.032 \\
\hline Negative & 53 & 29 & 24 & \\
\hline Positive & 63 & 22 & 41 & \\
\hline
\end{tabular}

TNM, tumor-nodes-metastasis; miR, microRNA.
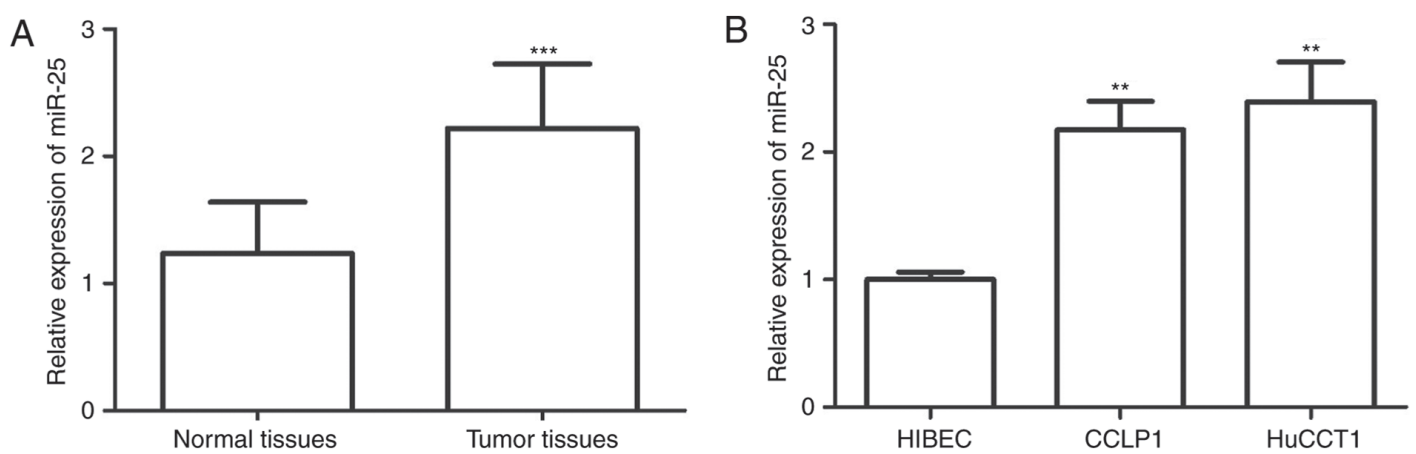

Figure 1. Expression of miR-25 was determined by reverse transcription-quantitative PCR. (A) The expression of miR-25 in CCA tissues was higher than that in adjacent normal tissues. (B) miR-25 was also overexpressed in CCA cell lines (CCLP1 and HuCCT1) compared with that in the HIBEC. ${ }^{* *} \mathrm{P}<0.01,{ }^{* * * *} \mathrm{P}<0.001$ vs. normal tissue/HIBEC. miR, microRNA; CCA, cholangiocarcinoma; HIBEC, human intrahepatic biliary epithelial cells.

$(\mathrm{P}=0.026)$ and lymph node metastasis $(\mathrm{P}=0.032)$. Patients with a high TNM stage had a higher expression level of miR-25 than those with a low stage $(\mathrm{P}=0.026)$, and compared with CCA patients with negative lymph node metastasis, miR-25 expression was significantly higher in those patients with lymph node metastasis $(\mathrm{P}=0.032)$. High miR-25 expression was significantly associated with high TNM stage $(\mathrm{P}=0.026)$ and lymph node metastasis $(\mathrm{P}=0.032)$. However, there was no association of miR-25 expression with other features, including age, gender and degree of differentiation (all $\mathrm{P}>0.05$; Table I).

Prognostic significance of miR-25 in CCA. To determine the prognostic value of miR-25 expression in CCA, Kaplan-Meier survival curve analysis was used. The results indicated that the 5-year survival rate in the low miR-25 expression group was higher than that in the high miR-25 expression group, and the difference was statistically significant (log-rank test $\mathrm{P}=0.022$; Fig. 2). Univariate and multivariate Cox regression analysis demonstrated that miR-25 expression was an independent prognostic predictor for overall survival in CCA patients (hazard ratio $=2.094,95 \% \mathrm{CI}=1.051-4.171, \mathrm{P}=0.036$; Table II).

Silencing of miR-25 reduces viability, migration and invasion ofCCA cells. To determine the effects of miR-25 on cell viability in CCA, the CCLP1 and HuCCT1 cell lines were transfected with miR-25 mimics or miR-25 inhibitor. RT-qPCR confirmed that the expression of miR-25 in CCA cells transfected with miR-25 mimics was significantly elevated, while in cells transfected with the miR-25 inhibitor, the expression was decreased, compared with that in the mock-transfected group $(\mathrm{P}<0.05$; 
Table II. Univariate and multivariate Cox logistic regression analysis of the influence of clinical parameters on overall survival.

\begin{tabular}{|c|c|c|c|c|c|c|}
\hline \multirow[b]{2}{*}{ Characteristics } & \multicolumn{3}{|c|}{ Univariate analysis } & \multicolumn{3}{|c|}{ Multivariate analysis } \\
\hline & HR & $95 \% \mathrm{CI}$ & P-value & HR & $95 \% \mathrm{CI}$ & P-value \\
\hline miR-25 (<2.219 vs. $\geq 2.219)$ & 2.006 & $1.056-3.811$ & 0.034 & 2.094 & $1.051-4.171$ & 0.036 \\
\hline Age $(<60$ vs. $\geq 60)$ & 1.105 & $0.597-2.046$ & 0.750 & $\mathrm{n} / \mathrm{a}$ & $\mathrm{n} / \mathrm{a}$ & $\mathrm{n} / \mathrm{a}$ \\
\hline Sex (Male vs. Female) & 0.966 & $0.528-1.764$ & 0.909 & $\mathrm{n} / \mathrm{a}$ & $\mathrm{n} / \mathrm{a}$ & $\mathrm{n} / \mathrm{a}$ \\
\hline Differentiation (Well vs. Moderate + poor) & 1.250 & $0.676-2.310$ & 0.477 & $\mathrm{n} / \mathrm{a}$ & $\mathrm{n} / \mathrm{a}$ & $\mathrm{n} / \mathrm{a}$ \\
\hline TNM stage (I-II vs. III-IV) & 0.895 & $0.490-1.636$ & 0.719 & $\mathrm{n} / \mathrm{a}$ & $\mathrm{n} / \mathrm{a}$ & $\mathrm{n} / \mathrm{a}$ \\
\hline Lymph node metastasis (negative vs. positive) & 0.996 & $0.545-1.819$ & 0.989 & $\mathrm{n} / \mathrm{a}$ & $\mathrm{n} / \mathrm{a}$ & $\mathrm{n} / \mathrm{a}$ \\
\hline
\end{tabular}

miR, microRNA; HR, hazard ratio; TNM, tumor-nodes-metastasis; n/a, not applicable.

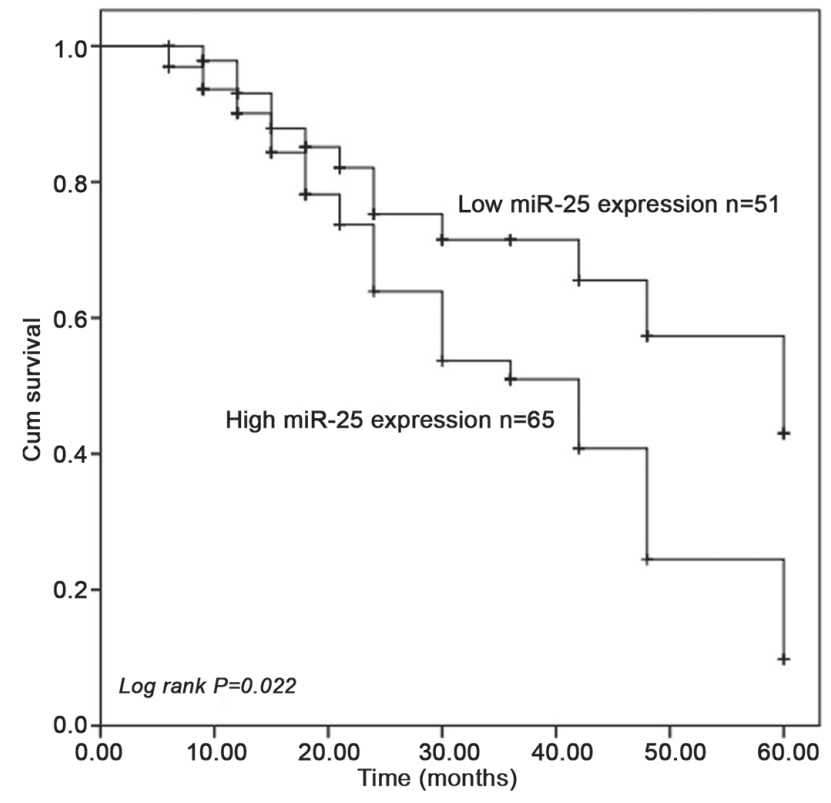

Figure 2. Overall survival was analyzed using Kaplan-Meier survival curves. Patients with high miR-25 expression levels had a shorter survival rate than those with low expression levels. Cum, cumulative; miR, microRNA.

Fig. 3A). An MTT assay was used to evaluate the effect of transfection on cell viability, and the results indicated that cell viability significantly increased in the cells transfected with the miR-25 mimics but was markedly decreased following transfection with the miR-25 inhibitor compared with that in the mock group $(\mathrm{P}<0.05$; Fig. 3B). In addition, transfection with the miR-25 mimics increased the cologenicity of CCA cells, while miR-25 inhibitor had a suppressive effect in the colony formation assays ( $\mathrm{P}<0.05$; Fig. $3 \mathrm{C}$ and $\mathrm{D})$. These observations indicated that miR-25 promotes the viability of CCA cells.

To investigate the effects of miR-25 on CCA metastasis, the cell migration and invasive capabilities of CCLP1 and HuCCT1 cells transfected with miR-25 mimics or inhibitor were examined. The results indicated that, compared with those in the mock-transfected group, the migration and invasion capacities of CCA cells transfected with the miR-25 inhibitor were significantly decreased, but were enhanced in cells transfected with miR-25 mimics ( $\mathrm{P}<0.05$; Fig. 4A-D).

\section{Discussion}

Although being considered a rare tumor, owing to its highly chemo-resistant characteristics and late diagnosis, CCA remains a refractory disease with poor long-term overall survival. Therefore, the prognosis of CCA patients urgently requires to be improved. A number of studies have reported that certain molecular biomarkers have crucial roles in tumor pathogenesis and development, and are highly associated with the prognosis for human malignant disease (19-21). Various prognostic biomarkers have also been identified in CCA. For instance, Phanthaphol et al (22) demonstrated that the upregulation of translationally-controlled tumor protein (TCTP) was associated with CCA progression and metastasis, while suppression of TCTP may serve as a potential therapeutic strategy for CCA. A member of the voltage-gated $\mathrm{K}$ channel superfamily, $\mathrm{KCa} 3.1$, was indicated to be a promising therapeutic target in intrahepatic CCA (23). Daya et al (24) demonstrated that progranulin has a critical role in tumor metastasis mediated via the epithelial to mesenchymal transition and was associated with prognosis. These studies suggest that the development of cancer-associated genes may help improving prognosis and explore more therapeutic targets for identifying novel therapeutic strategies for patients.

miR-25 belongs to the miR-106b 25 cluster, which is located within the 13 th intron of minichromosome maintenance complex component 7 , an oncogene acting in cooperation with the aforementioned cluster in promoting cancer progression (25). A number of studies demonstrated that the miR-106b 25 cluster has numerous biological functions in development, including viability and differentiation (26). For instance, a study by Khuu et al (25), indicated that the role of miRNAs encoded by the miR-106b 25 cluster is also associated with the growth and maintenance of stem/progenitor cells. Proper regulation of stem cell differentiation is crucial to normal development (27). Aberrant miRNA expression patterns have been reported to contribute to the progression and prognosis of various cancer types $(28,29)$. A number of studies have indicated that miR-25 functions as an oncogene in multiple types of malignancy, including non-small cell lung cancer (NSCLC) and gastric cancer $(13,14)$. In CCA, miR-25 was also indicated to be overexpressed and negatively regulate 

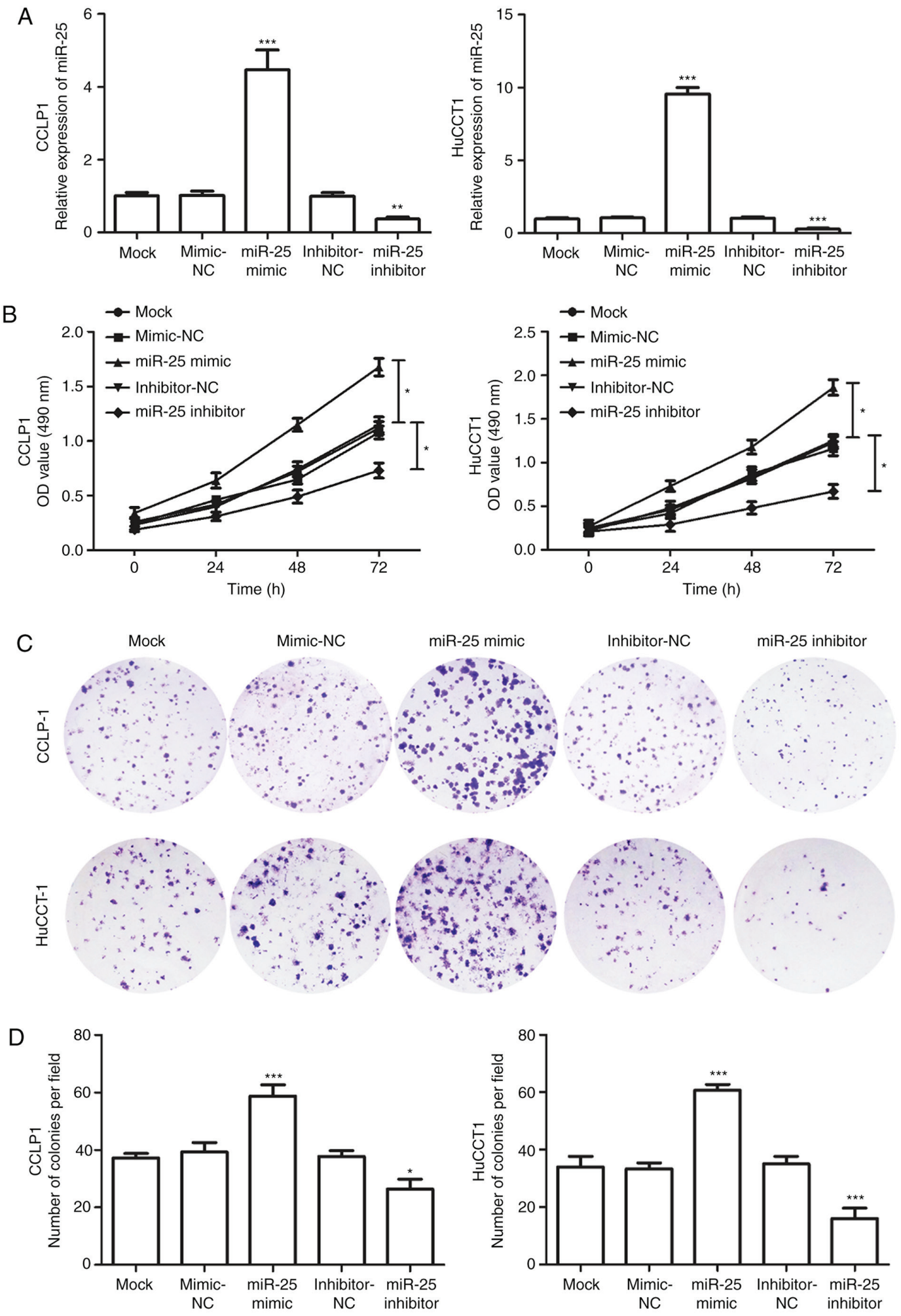

Figure 3. Effects of miR-25 on cell viability in CCLP1 and HuCCT1 cells. (A) The expression of miR-25 was increased in cells transfected with miR-25 mimics but downregulated in cells transfected with miR-25 inhibitor. (B) The MTT assay indicated that cell viability was enhanced by overexpression of miR-25, but was suppressed by downregulation of miR-25. " $\mathrm{P}<0.05$ as indicated. (C and D) The viability of CCLP1 and HuCCT1 cells was assessed using a colony formation assay. (C) Representative images of colony formation (magnification, $\mathrm{x} 40$ ) and (D) quantified number of colonies per field. ${ }^{*} \mathrm{P}<0.05,{ }^{* * *} \mathrm{P}<0.01,{ }^{* * * *} \mathrm{P}<0.001$ vs. mock. miR, microRNA; OD, optical density; NC, negative control.

apoptosis signaling (30). However, the prognostic value of miR-25 in CCA has remained elusive.

To expand the current knowledge of the role of miR-25 in $\mathrm{CCA}$, its expression pattern was assessed in CCA tissues and cell lines, and its prognostic significance in CCA patients was explored. In the present study, the relative expression of miR-25 in CCA tissues and cell lines was significantly upregulated when compared with that in adjacent normal tissues and a normal cell line, respectively. These results were consistent with those of Razumilava et al (30), which 

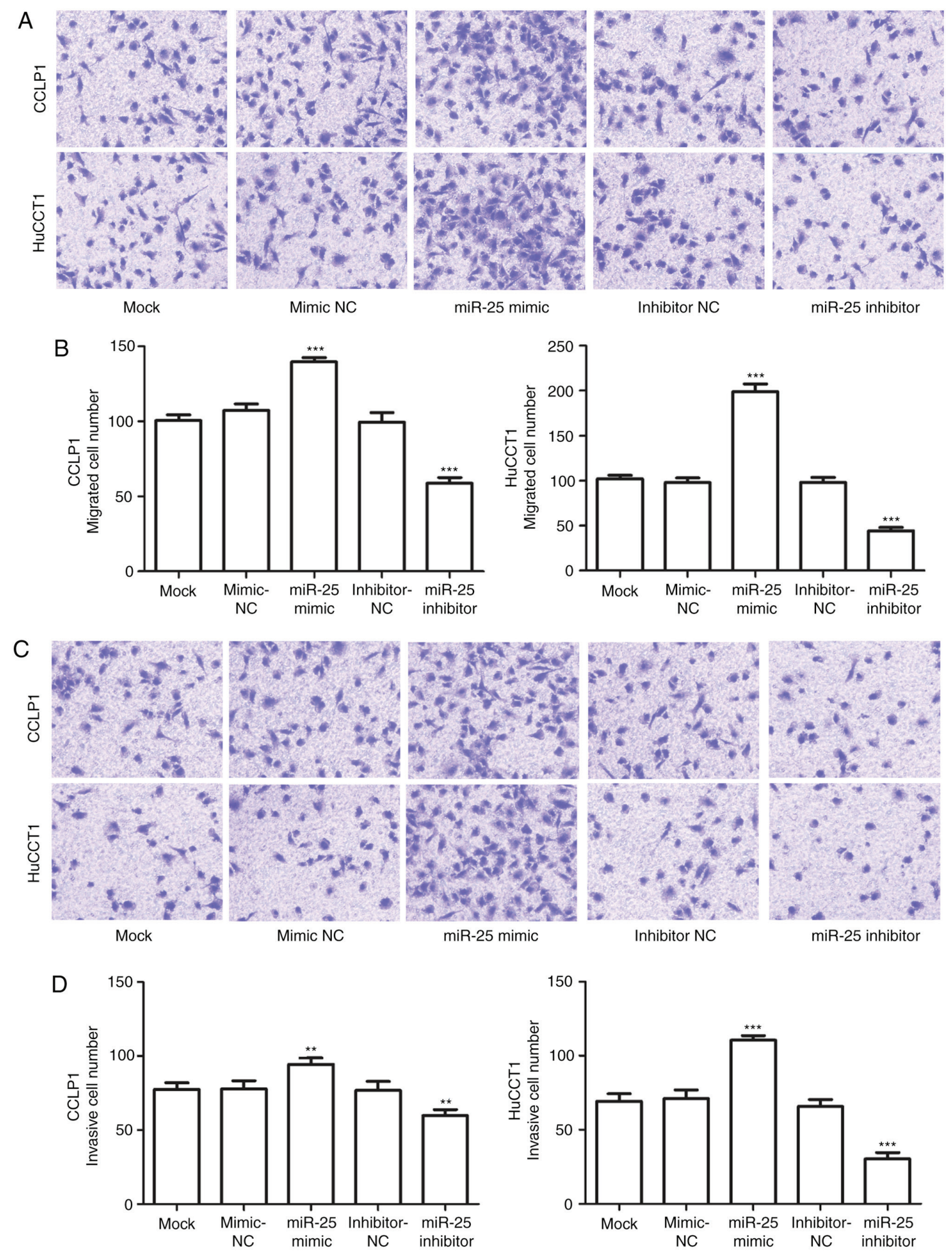

Figure 4. Migration and invasion of CCLP1 and HuCCT1 cells. Transwell migration assay with CCLP1 and HuCCT1 cells. (A) Representative images (magnification, $\mathrm{x} 100$ ) and (B) quantified numbers of migrated cells. miR-25 mimics enhanced and miR-25 inhibitor reduced the cell migration. Transwell invasion assay with CCLP1 and HuCCT1 cells. (C) Representative images (magnification, $\mathrm{x} 100$ ) and (D) quantified numbers of invaded cells. miR-25 mimics promoted and miR-25 inhibitor suppressed the cell invasion. ${ }^{* *} \mathrm{P}<0.01,{ }^{* * * *} \mathrm{P}<0.001$ vs. mock. miR, microRNA; NC, negative control.

demonstrated that miR-25 is upregulated in malignant CCA cell lines as well as in patients tissue samples, compared with benign cells and benign adjacent tissue samples, respectively. Furthermore, the association between the expression of miR-25 and the clinical features of CCA patients was analyzed, revealing that miR-25 was significantly associated with TNM stage and lymph node metastasis, i.e. that patients with a high TNM stage and positive lymph node metastasis may have higher miR-25 expression. These above results suggest that miR-25 may be an oncogene in CCA tumorigenesis and is involved in the development of CCA. Considering miR-25 expression was significantly associated with TNM 
stage and lymph node metastasis, it was hypothesized that miR-25 expression may be associated with the prognosis of CCA patients. To further investigate the prognostic role of miR-25 in CCA patients, Kaplan-Meier and Cox regression analyses were performed. First, it was revealed that the expression of miR-25 was significantly correlated with clinicopathological factors. miR-25 was also significantly associated with the overall survival of CCA patients. The Kaplan-Meier analysis indicated that patients in the high miR-25 expression group had a shorter survival rate than those in the low miR-25 expression group. Finally, miR-25 was identified as an independent biomarker for patients with CCA by multivariate Cox analysis. Taken together, the present results demonstrate that miR-25 is a prognostic biomarker for CCA. A comparison between miR-25 expression and different TNM stages of CCA patients to determine whether miR-25 has diagnostic value in differentiating between CCA patients in different stages will be performed in a future study.

Recent studies have indicated the effects of miR-25 on biological behaviors during cancer progression and metastasis. For instance, miR-25 promotes gastric cancer viability, migration and invasion, and is associated with poor prognosis (31). To investigate the function of miR-25 in CCA cells, miR-25 mimics and inhibitor were employed and their effects on the biological behaviour of CCA cell lines were assessed. The results demonstrated that miR-25 mimics enhanced the cell viability, migration and invasion, while miR-25 inhibitor had a dampening effect, which suggested that downregulation of miR-25 expression inhibits CCA progression. Although a significant difference in transfection efficiency between two CCA cell lines was observed, the difference in biological functions was not proportionally pronounced. Cancer cells exhibit different degrees of differentiation which can produce cells with different morphological and functional features (32). Various molecular pathways regulated by miR-25 have been studied in a number of cancer types. For instance, a study by Ding et al (33) demonstrated that miR-25 activates the ERK signaling pathway by directly targeting kruppel-like factor 4, promoting NSCLC cell migration and invasion. A recent study by Sanchez-Mejias et al (34) validated suppressor of cytokine signaling 5 (SOCS5) as a bona fide target of miR-25 and identified novel molecular targets for potential drug discovery efforts to fight hepatocellular carcinoma. Another study by Long et al (35) demonstrated that miR-58-5-5p promotes cancer stem cell characteristics and chemoresistance via targeting multiple negative regulators of the STAT3 signaling pathway, including SOCS5, leading to constitutive activation of STAT3 signaling. Therefore, it may be speculated that miR-25 may also active the STAT3 signaling pathway by targeting SOCS5, to thereby regulate the progression of CCA. In addition to these in vitro results, the detailed molecular mechanisms of miR-25 in CCA requires further elucidation.

In conclusion, the present study demonstrated that overexpression of miR-25 was associated with poor prognosis of CCA patients and promoted cell viability, migration, and invasion of CCA cells in vitro. The present results provide evidence that miR-25 may be a promising prognostic biomarker and potential therapeutic target for the treatment of CCA patients.

\section{Acknowledgements}

Not applicable.

\section{Funding}

No funding was received.

\section{Availability of data and materials}

The datasets used and/or analyzed during the present study are available from the corresponding author on reasonable request.

\section{Authors' contributions}

HL and JW designed the study. HL and LM performed the experiments, analyzed the data and prepared the manuscript.

\section{Ethics approval and consent to participate}

All patients provided written informed consent to participate in this study. Tissue collection and the study protocol were approved by the Research Ethics Committee of Yidu Central Hospital (Weifang, China).

\section{Patient consent for publication}

Not applicable.

\section{Competing interests}

The authors declare that they have no competing interests.

\section{References}

1. Blechacz B and Gores GJ: Cholangiocarcinoma: Advances in pathogenesis, diagnosis, and treatment. Hepatology 48: 308-321, 2008.

2. Blechacz B: Cholangiocarcinoma: Current knowledge and new developments. Gut Liver 11: 13-26, 2017.

3. Fairweather M, Balachandran VP and D'Angelica MI: Surgical management of biliary tract cancers. Chin Clin Oncol 5: 63, 2016.

4. Razumilava N and Gores GJ: Cholangiocarcinoma. Lancet 383: 2168-2179, 2014.

5. Cho MS, Kim SH, Park SW, Lim JH, Choi GH, Park JS, Chung JB and Kim KS: Surgical outcomes and predicting factors of curative resection in patients with hilar cholangiocarcinoma: 10-year single-institution experience. J Gastrointest Surg 16: 1672-1679, 2012.

6. Jarnagin WR, Fong Y, DeMatteo RP, Gonen M, Burke EC, Bodniewicz BS J, Youssef BA M, Klimstra D and Blumgart LH: Staging, resectability, and outcome in 225 patients with hilar cholangiocarcinoma. Ann Surg 234: 507-517; discussion 517-509, 2001.

7. Romero-Cordoba SL, Salido-Guadarrama I, RodriguezDorantes $\mathrm{M}$ and Hidalgo-Miranda A: miRNA biogenesis: Biological impact in the development of cancer. Cancer Biol Ther 15: 1444-1455, 2014

8. Tufekci KU, Oner MG, Meuwissen RL and Genc S: The role of microRNAs in human diseases. Methods Mol Biol 1107: 33-50, 2014.

9. Singh RP, Massachi I, Manickavel S, Singh S, Rao NP, Hasan S, Mc Curdy DK, Sharma S, Wong D, Hahn BH and Rehimi H: The role of miRNA in inflammation and autoimmunity. Autoimmun Rev 12: 1160-1165, 2013.

10. Chen L, Song J, Cui J, Hou J, Zheng X, Li C and Liu L: microRNAs regulate adipocyte differentiation. Cell Biol Int 37: 533-546, 2013.

11. Di Leva G, Garofalo M and Croce CM: MicroRNAs in cancer. Annu Rev Pathol 9: 287-314, 2014. 
12. Zhao L, Fan W, Fan Y and Gao S: MicroRNA-214 promotes the proliferation, migration and invasion of gastric cancer MKN28 cells by suppressing the expression of Dact2. Exp Ther Med 16: 4909-4917, 2018.

13. Xiang J, Hang JB, Che JM and Li HC: MiR-25 is up-regulated in non-small cell lung cancer and promotes cell proliferation and motility by targeting FBXW7. Int J Clin Exp Pathol 8: 9147-9153, 2015.

14. Zhou J, Wang W, Li W, Wu L, Li G, Shi J and Zhou S: The polymorphism in miR-25 attenuated the oncogenic function in gastric cancer. Tumour Biol 37: 5515-5520, 2016.

15. Zhang J, Gong X, Tian K, Chen D, Sun J, Wang G and Guo M: miR-25 promotes glioma cell proliferation by targeting CDKN1C. Biomed Pharmacother 71: 7-14, 2015.

16. Wang C, Wang X, Su Z, Fei H, Liu X and Pan Q: MiR-25 promotes hepatocellular carcinoma cell growth, migration and invasion by inhibiting RhoGDI1. Oncotarget 6: 36231-36244, 2015.

17. Wang H, Li C, Jian Z, Ou Y and Ou J: TGF-betal reduces mir-29a expression to promote tumorigenicity and metastasis of cholangiocarcinoma by targeting HDAC4. PloS One 10 : e0136703, 2015

18. Livak KJ and Schmittgen TD: Analysis of relative gene expression data using real-time quantitative PCR and the 2(-Delta Delta C(T)) method. Methods 25: 402-408, 2001

19. Dumortier M, Ladam F, Damour I, Vacher S, Bieche I, Marchand N, de Launoit Y, Tulasne D and Chotteau-Lelievre A: ETV4 transcription factor and MMP13 metalloprotease are interplaying actors of breast tumorigenesis. Breast Cancer Res 20: 73, 2018

20. Gomez-Macias GS, Garza-Rodriguez ML, Garza-Guajardo R, Monsivais-Ovalle D, Ancer-Rodriguez J, Barrera-Saldana HA and Barboza-Quintana O: Overexpression of the matrix metalloproteinase 11 gene is a potential biomarker for type 1 endometrial cancer. Oncol Lett 16: 1073-1078, 2018.

21. Sotgiu ML: Effects of alpha 2-adrenoceptors blockade on the inhibition of the nociceptive jaw-opening reflex by the lateral reticular nucleus in rabbits. Arch Ital Biol 127: 63-67, 1989.

22. Phanthaphol N, Techasen A, Loilome W, Thongchot S, Thanan R, Sungkhamanon S, Khuntikeo N, Yongvanit P and Namwat N: Upregulation of TCTP is associated with cholangiocarcinoma progression and metastasis. Oncol Lett 14: 5973-5979, 2017.

23. Song P, Du Y, Song W, Chen H, Xuan Z, Zhao L, Chen J, Guo D, Jin C, Zhao Y, et al: KCa3.1 as an effective target for inhibition of growth and progression of intrahepatic cholangiocarcinoma. J Cancer 8: 1568-1578, 2017.
24. Daya M, Loilome W, Techasen A, Thanee M, Sa-Ngiamwibool P, Titapun A, Yongvanit P and Namwat N: Progranulin modulates cholangiocarcinoma cell proliferation, apoptosis, and motility via the PI3K/pAkt pathway. Onco Targets Ther 11: 395-408, 2018.

25. Khuu C, Utheim TP and Sehic A: The three paralogous MicroRNA clusters in development and disease, miR-17-92, miR-106a-363, and miR-106b-25. Scientifica (Cairo) 2016: 1379643, 2016.

26. Brett JO, Renault VM, Rafalski VA, Webb AE and Brunet A: The microRNA cluster miR-106b 25 regulates adult neural stem/progenitor cell proliferation and neuronal differentiation. Aging (Albany NY) 3: 108-124, 2011.

27. Zwaka TP and Thomson JA: Differentiation of human embryonic stem cells occurs through symmetric cell division. Stem Cells 23: 146-149, 2005.

28. Ehrlich L, Hall C, Venter J, Dostal D, Bernuzzi F, Invernizzi P, Meng F, Trzeciakowski JP, Zhou T, Standeford H, et al: miR-24 Inhibition increases menin expression and decreases cholangiocarcinoma proliferation. Am J Pathol 187: 570-580, 2017.

29. Wu C, Zhang J, Cao X, Yang Q and Xia D: Effect of Mir-122 on human cholangiocarcinoma proliferation, invasion, and apoptosis through P53 expression. Med Sci Monit 22: 2685-2690, 2016.

30. Razumilava N, Bronk SF, Smoot RL, Fingas CD, Werneburg NW, Roberts LR and Mott JL: miR-25 targets TNF-related apoptosis inducing ligand (TRAIL) death receptor- 4 and promotes apoptosis resistance in cholangiocarcinoma. Hepatology 55: 465-475, 2012.

31. Li BS, Zuo QF, Zhao YL, Xiao B, Zhuang Y, Mao XH, Wu C, Yang SM, Zeng H, Zou QM and Guo G: MicroRNA-25 promotes gastric cancer migration, invasion and proliferation by directly targeting transducer of ERBB2, 1 and correlates with poor survival. Oncogene 34: 2556-2565, 2015.

32. Wang M, Yang YO, Jin Q, Shang L and Zhang J: Function of miR-25 in the invasion and metastasis of esophageal squamous carcinoma cells and bioinformatical analysis of the miR-106b-25 cluster. Exp Ther Med 15: 440-446, 2018.

33. Ding X, Zhong T, Jiang L, Huang J, Xia Y and Hu R: miR-25 enhances cell migration and invasion in non-small-cell lung cancer cells via ERK signaling pathway by inhibiting KLF4. Mol Med Rep 17: 7005-7016, 2018.

34. Sanchez-Mejias A, Kwon J, Chew XH, Siemens A, Sohn HS, Jing G, Zhang B, Yang $\mathrm{H}$ and Tay Y: A novel SOCS5/miR-18/miR-25 axis promotes tumorigenesis in liver cancer. Int J Cancer 144: 311-321, 2019.

35. Long J, Jiang C, Liu B, Dai Q, Hua R, Chen C, Zhang B and $\mathrm{Li} \mathrm{H}$ : Maintenance of stemness by miR-589-5p in hepatocellular carcinoma cells promotes chemoresistance via STAT3 signaling. Cancer Lett 423: 113-126, 2018. 